\title{
Stromal p16 Overexpression in Adult Granulosa Cell Tumors of the Ovary
}

\author{
KIYONG NA ${ }^{1}$, JI-YOUN SUNG ${ }^{2}$ and HYUN-SOO KIM ${ }^{1}$ \\ ${ }^{1}$ Department of Pathology, Severance Hospital, Yonsei University College of Medicine, Seoul, Republic of Korea; \\ ${ }^{2}$ Department of Pathology, Kyung Hee University College of Medicine, Seoul, Republic of Korea
}

\begin{abstract}
Background/Aim: Adult granulosa cell tumor of the ovary is usually diagnosed at an early stage. However, most patients with advanced or recurrent disease will die of the disease due to limited treatment options. Data on the stromal p16 expression of ovarian adult granulosa cell tumors are limited. The aim of this study was to analyze the immunohistochemical p16 expression in the peritumoral stroma of primary and recurrent adult granulosa cell tumors and investigate whether there were significant differences in stromal p16 expression among nonpathological ovaries, benign sex cord-stromal tumors, and adult granulosa cell tumors. Materials and Methods: This study included 13 and 11 cases of primary and recurrent adult granulosa cell tumors, respectively. Nonpathological ovaries and benign sex cord-stromal tumors showed negative or weak positive expression, whereas most of the adult granulosa cell tumors showed diffuse and moderate-to-strong immunostaining. Results: Primary adult granulosa cell tumors had significantly higher stromal p16 expression levels than nonpathological ovaries and benign sex cord-stromal tumors $(p<0.001)$. Moreover, recurrent adult granulosa cell tumors showed significantly elevated levels of stromal p16 expression compared to primary adult granulosa cell tumors $(p=0.032)$. In contrast, the difference in stromal p16 expression between non-pathological ovaries and benign sex cord-stromal tumors was not statistically significant $(p=0.522)$. Conclusion: Our observations suggest that stromal p16 expression may be involved in the development and progression of ovarian adult granulosa cell tumors.
\end{abstract}

Correspondence to: Hyun-Soo Kim, Department of Pathology, Severance Hospital, Yonsei University College of Medicine, 50-1, Yonsei-ro, Seodaemun-gu, Seoul 03722, Republic of Korea. Tel: +82 222281794, +82 23620860; e-mail: hyunsookim@yuhs.ac

Key Words: Ovary, adult granulosa cell tumor, peritumoral stroma, p16, immunohistochemistry.
Adult granulosa cell tumor of the ovary is the most common malignant sex cord-stromal tumor. It constitutes $2-4 \%$ of all ovarian malignancies (1-3). Adult granulosa cell tumors are characterized by slow growth with an indolent course; however, recurrences are possible even after more than one decade (3). It is evident that patients with this tumor have recurrent disease, which typically is the eventual cause of death $(4,5)$. For this reason, prolonged follow-up is necessary. Due to the rarity of adult granulosa cell tumors, the prognostic factors of tumor recurrence are uncertain, although some clinical and pathological parameters, such as advanced stage at the time of initial diagnosis, larger tumor size, higher mitotic index, tumor rupture, and presence of residual tumor after initial surgery, have been reported to be associated with a higher risk of recurrence $(4,5)$. The pathogenesis and cellular pathways that regulate cellular proliferation and survival of adult granulosa cell tumors remain poorly understood.

The protein p16 is the principal member of the cyclindependent kinase inhibitors (6). As a regulatory protein of the cell cycle, p16 is involved in the $G_{1}$-to-S phase transition. Upon binding to cyclin-dependent kinase inhibitor 4/6, p16 inhibits cyclin D1-cyclin-dependent kinase inhibitor 4/6 complex formation and cyclin-dependent kinase 4/6mediated phosphorylation of retinoblastoma protein. Once retinoblastoma is phosphorylated, the E2 factorretinoblastoma complex dissociates, leading to reduced growth-suppressor retinoblastoma activity (7). Like retinoblastoma protein, $\mathrm{p} 16$ is a tumor suppressor; p16 maintains retinoblastoma protein family members in a hypophosphorylated state (8-10). However, it is difficult to explain many aspects of p16 function and regulation by its well-known function as a tumor suppressor alone. In addition, the molecular pathways responsible for $\mathrm{p} 16$ function and expression have not yet been elucidated.

The expression of p16 has been analyzed in some studies regarding gynecological tumors. According to the 2014 World Health Organization (WHO) Classification of Tumours of Female Reproductive Organs (11), more than half of ovarian 
high-grade serous carcinomas show strong and diffuse p16 expression. The majority of endometrial serous carcinomas also strongly express p16 protein. p16 and p53 expression levels are used as differential immunostaining markers to distinguish high-grade serous carcinoma from other histological types of ovarian carcinomas and distinguish serous carcinomas from other histological types of endometrial carcinoma. In addition, p16 overexpression occurs in human papillomavirus-related tumors $(6,11)$. p16 overexpression, so-called p16 block positivity, indicates highrisk human papillomavirus infection, not only in uterine cervical squamous cell carcinoma and usual-type endocervical adenocarcinoma, but also in endocervical adenocarcinoma in situ and high-grade squamous intraepithelial lesions of the uterine cervix, vulva, vagina, and anogenital regions. Therefore, p16 is used as a diagnostic biomarker for distinguishing human papillomavirus-related precancerous lesions and invasive carcinomas from benign mimics such as reactive squamous metaplasia, atrophy, reparative epithelial changes, or tangential sectioning (12-14).

However, conflicting patterns of p16 expression have been reported, which further complicates the understanding of its pathophysiological roles. p16 expression is either overexpressed (15-19) or down-regulated (20-22) in different types of human malignancy. Recently, during the routine diagnosis of primary and recurrent adult granulosa cell tumor resection specimens, we noticed p16 overexpression in the peritumoral stroma, but not in tumor cells. Although p16 is commonly used as a biomarker for diagnosing various gynecological malignancies, its expression in the stromal component of adult granulosa cell tumors has not yet been studied as far as we are aware of. In this study, we examined stromal p16 expression in adult granulosa cell tumors using immunohistochemical staining and investigated whether a significant difference existed in stromal p16 immunoreactivity among non-pathological ovaries, benign sex cord-stromal tumors, and primary and recurrent adult granulosa cell tumors.

\section{Materials and Methods}

Tissue specimens. Cases from January 2015 through December 2016 were selected from the computerized files of the Department of Pathology, Severance Hospital, Yonsei University College of Medicine, Seoul, Republic of Korea. A thorough search was performed using the key words "ovary", "granulosa cell tumor", "adult granulosa cell tumor", "malignant granulosa cell tumor", "recurrent adult granulosa cell tumor", and "recurrent malignant granulosa cell tumor" among the archival surgical pathology cases. Pathological diagnoses were established following the criteria of the revised 2014 WHO Classification of Tumours of Female Reproductive Organs (11). Clinical and pathological information was obtained from the electrical medical information systems and the pathology reports. Clinical details that were reviewed included the age of each patient at the time of diagnosis, location of the primary adult granulosa cell tumor, surgical treatment for the primary adult granulosa cell tumor, International Federation of Gynecology and Obstetrics stage of the primary adult granulosa cell tumor, postoperative treatment for the primary adult granulosa cell tumor, location of the recurrent adult granulosa cell tumor, surgical treatment for the recurrent adult granulosa cell tumor, and postoperative treatment for the recurrent adult granulosa cell tumor. Five nonpathological ovaries and 13 benign ovarian sex cordstromal tumors, including five conventional fibromas, two cellular fibromas, two thecomas, two sclerosing stromal tumors, and two microcystic stromal tumors, were also collected. This study was reviewed and approved by the Institutional Review Board at the Severance Hospital, Yonsei University Health System, Seoul, Republic of Korea (2016-1971-001).

Histopathological examination. The resected specimens were fixed in $10 \%$ neutral-buffered formalin and embedded in paraffin blocks. From each formalin-fixed, paraffin-embedded tissue block, 4- $\mu \mathrm{m}-$ thick sections were cut and stained with hematoxylin and eosin. A Board-certified pathologist specializing in gynecological oncology examined all available hematoxylin and eosin-stained slides by routine light microscopy and chose the most representative slides to perform immunohistochemical staining.

Immunohistochemical staining. The 4- $\mu$ m-thick, formalin-fixed, paraffin-embedded tissue sections were deparaffinized and rehydrated with a xylene and alcohol solution. Immunohistochemical staining was performed using a Ventana Benchmark XT automated staining system (Ventana Medical Systems, Tucson, AZ, USA) or Dako Omnis (Dako, Agilent Technologies, Inc., Carpinteria, CA, USA) according to the manufacturer's instructions. Antigen retrieval was performed using Cell Conditioning Solution (CC1; Ventana Medical Systems) or EnVision FLEX Target Retrieval Solution, High pH (Dako). Sections were incubated with primary antibodies against p16 (prediluted, clone E6H4; Ventana Medical Systems), inhibin- $\alpha$ (1:50; clone R1; Bio-Rad Laboratories, Hercules, CA, USA), calretinin (1:100; polyclonal; Cell Marque, Rocklin, CA, USA), CD56 (1:100; clone CD564; Novocastra, Leica Biosystems, Newcastle Upon Tyne, UK), CD99 (1:200; clone 12E7; Dako), smooth muscle actin (1:500; clone 1A4; Dako), and epithelial membrane antigen (1:200; clone E29; Dako). After chromogenic visualization, using UltraView Universal DAB Detection Kits (Ventana Medical Systems) or EnVision FLEX /HRP (Dako), slides were counterstained with hematoxylin. Appropriate positive and negative controls were concurrently stained to validate the staining method.

The percentage of p16-positive stromal cells and staining intensity were assessed. The estimated percentages were categorized as follows: absent (score 0), less than $10 \%$ (score 1), $10 \%$ to $24 \%$ (score 2 ), $25 \%$ to $49 \%$ (score 3 ), or $50 \%$ or more (score 4 ). The staining intensity was graded as follows: negative (score 0 ), weak (score 1), moderate (score 2), or strong (score 3). The subcellular locations of p16-positive signals (nuclear or cytoplasmic) were also estimated. The final immunoreactivity score was calculated as the product of the percentage and staining intensity scores, resulting in scores of $0,1,2,3,4,6,8,9$, or $12(18,19)$. The immunoreactivity scores were categorized as follows: 0 as negative; 1,2 , and 3 as weakly positive; 4 and 6 as moderately positive; and 8,9 , and 12 as strongly positive. 
Statistical analysis. Linear-by-linear association tests were performed to compare the status of stromal p16 expression among nonpathological ovaries, benign sex cord-stromal tumors, and primary and recurrent adult granulosa cell tumors. Statistical analyses were performed using PASW Statistics 18 (IBM SPSS, Chicago, IL, USA). Statistical significance was set at $p<0.05$.

\section{Results}

Patient demographics. The clinicopathological characteristics of 24 patients with adult granulosa cell tumors are summarized in Table I. The ages of the patients ranged from 28 to 72 years (median: 51 years). Ten $(41.7 \%)$ patients were younger than 51 years. Thirteen out of the $24(54.2 \%)$ patients were diagnosed as having primary ovarian adult granulosa cell tumors. Six (46.2\%) patients underwent unilateral salpingo-oophorectomies, and three (23.1\%) underwent staging operations including total hysterectomies with bilateral $(2 / 13,15.4 \%)$ or unilateral $(1 / 13,7.7 \%)$ salpingo-oophorectomies, omentectomy, bilateral pelvic lymph node dissection, and paraaortic lymph node dissection $(2 / 13,15.4 \%)$ or sampling $(1 / 13,7.7 \%)$. The remaining patients underwent total hysterectomies with bilateral salpingo-oophorectomies $(2 / 13,15.4 \%)$, bilateral salpingooophorectomy $(1 / 13,7.7 \%)$, or unilateral oophorectomy $(1 / 13,7.7 \%)$. Ten $(76.9 \%)$ patients with primary ovarian adult granulosa cell tumors had stage IA tumors, and three (23.1\%) patients whose tumors showed ovarian surface extension were diagnosed as having stage IC tumors. None of the patients had stage II-IV tumors. After surgery, two (15.4\%) patients with stage IC tumors received postoperative adjuvant chemotherapy. Eleven out of the $24(45.8 \%)$ patients were diagnosed as having recurrent adult granulosa cell tumors. Eight out of the $11(72.7 \%)$ patients had recurrent tumors at multiple sites, whereas in the remaining three patients $(27.3 \%)$, tumors recurred at a single site. All 11 patients who developed recurrences underwent debulking surgeries. All 11 patients received postoperative chemotherapy following debulking surgery.

Pathological diagnosis of adult granulosa cell tumors. Microscopically, the tumor tissues revealed a proliferation of small, bland-appearing granulosa cells (Figure 1A). Various growth patterns, including diffuse, trabecular, microfollicular, macrofollicular, insular, and gyriform patterns, were noted. The intervening stroma consisted of bland-appearing, spindle-shaped, fibroblast-like cells. Some stellate-shaped cells with mild nuclear atypia were noted, but there was no significant nuclear pleomorphism in the stroma. In some cases, minimal to mild lymphoplasmacytic infiltration was observed. The individual tumor cells were cuboidal to polygonal, and possessed coffee bean-shaped, oval nuclei with longitudinal grooves or folds and relatively scant eosinophilic cytoplasm. Nuclear atypia were minimal
Table I. Clinicopathological characteristics of 24 adult granulosa cell tumors.

\begin{tabular}{|c|c|}
\hline Characteristic & Number of patients $(\%)$ \\
\hline \multicolumn{2}{|l|}{ Age } \\
\hline$<51$ Years & $10(41.7)$ \\
\hline$\geq 51$ Years & $14(58.3)$ \\
\hline \multicolumn{2}{|l|}{ Nature } \\
\hline Primary & $13(54.2)$ \\
\hline Recurrent & $11(45.8)$ \\
\hline \multicolumn{2}{|l|}{ Location of primary tumor } \\
\hline Right ovary & $6(46.2)$ \\
\hline Left ovary & $7(53.8)$ \\
\hline \multicolumn{2}{|l|}{ Surgical treatment for primary tumor } \\
\hline UO & $1(7.7)$ \\
\hline USO & $6(46.2)$ \\
\hline USO+OMT+BPLND+PALNS & $1(7.7)$ \\
\hline BSO & $1(7.7)$ \\
\hline $\mathrm{TH}+\mathrm{BSO}$ & $2(15.4)$ \\
\hline TH+BSO+OMT+BPLND+PALND & $2(15.4)$ \\
\hline \multicolumn{2}{|l|}{ FIGO stage of primary tumor } \\
\hline IA & $10(76.9)$ \\
\hline IB & $0(0.0)$ \\
\hline IC & $3(23.1)$ \\
\hline \multicolumn{2}{|l|}{ Postoperative treatment for primary tumor } \\
\hline Chemotherapy & $2(15.4)$ \\
\hline None & $11(84.6)$ \\
\hline \multicolumn{2}{|l|}{ Location of recurrent tumor } \\
\hline Diaphragm & $3(27.3)$ \\
\hline Stomach & $1(9.1)$ \\
\hline Spleen & $1(9.1)$ \\
\hline Small intestine & $1(9.1)$ \\
\hline Large intestine & $4(36.4)$ \\
\hline Pelvic peritoneum & $4(36.4)$ \\
\hline Abdominal peritoneum & $4(36.4)$ \\
\hline Omentum & $2(18.2)$ \\
\hline Lymph node & $1(9.1)$ \\
\hline \multicolumn{2}{|l|}{ Surgical treatment for recurrent tumor } \\
\hline Debulking surgery & $11(100.0)$ \\
\hline \multicolumn{2}{|l|}{ FIGO stage of recurrent tumor } \\
\hline II & $2(18.2)$ \\
\hline III & $9(81.8)$ \\
\hline \multicolumn{2}{|c|}{ Postoperative treatment for recurrent tumor } \\
\hline Chemotherapy & $11(100.0)$ \\
\hline None & $0(0.0)$ \\
\hline
\end{tabular}

BPLND: Bilateral pelvic lymph node dissection; BSO: bilateral salpingo-oophorectomy; FIGO: International Federation of Gynecology and Obstetrics; OMT: omentectomy; PALND: para-aortic lymph node dissection; PALNS: para-aortic lymph node sampling; TH: total hysterectomy; UO: unilateral oophorectomy; USO: unilateral salpingooophorectomy.

to mild, although some enlarged hyperchromatic nuclei were also observed in a few cases. Mitotic figures were detected at rates up to three per 10 high-power fields. No evidence of coagulative tumor cell necrosis or atypical mitosis was identified. Immunohistochemical staining confirmed adult granulosa cell tumor diagnosis. The tumor cells were 

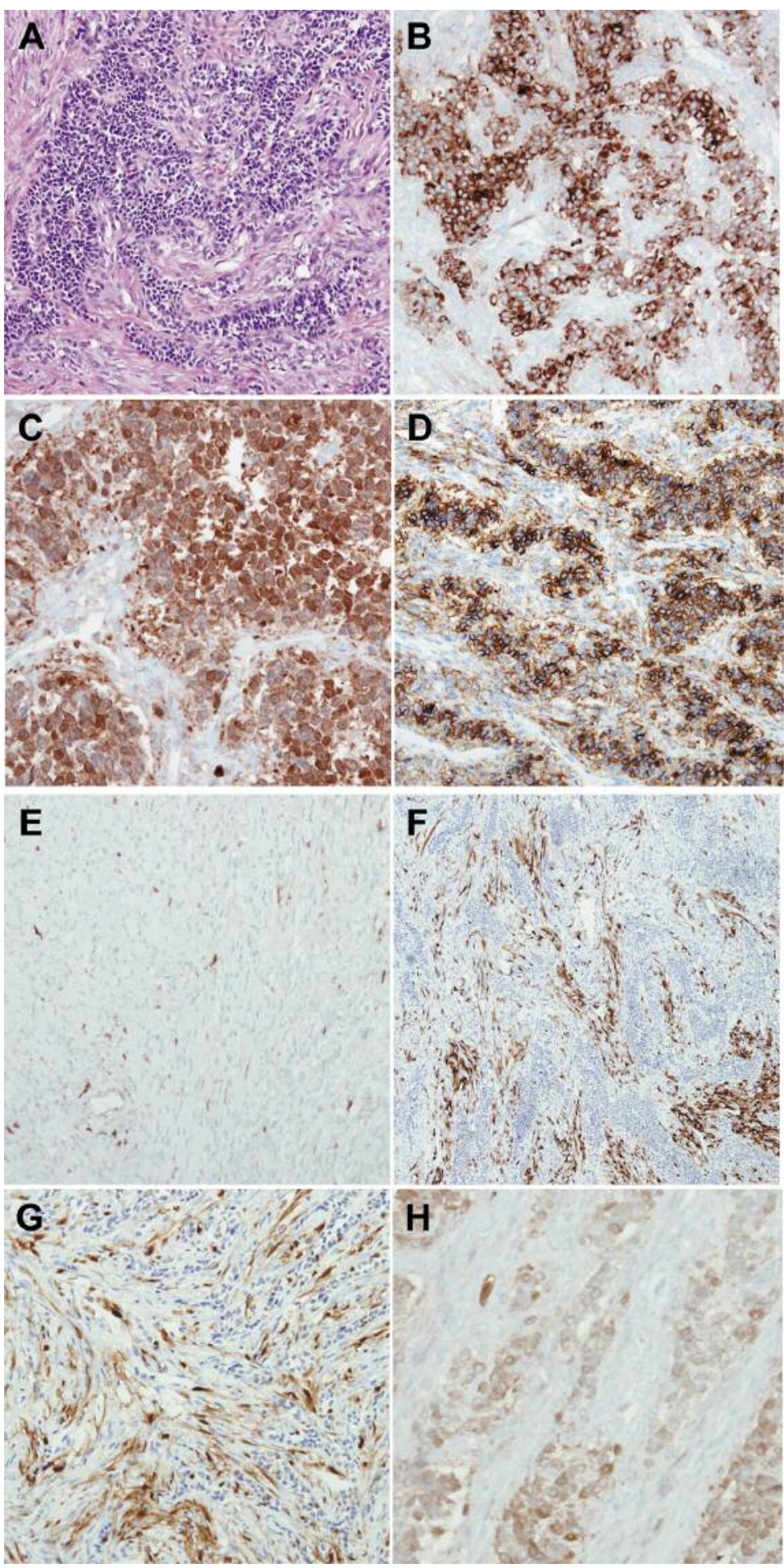

Figure 1. Stromal p16 expression (A to G) and tumor cells $(H)$ of ovarian adult granulosa cell tumors. An adult granulosa cell tumor is characterized by small, bland-appearing, cuboidal to polygonal tumor cells arranged in anastomosing trabeculae, nests, and cords (A). The diagnosis of adult granulosa cell tumor was confirmed by positive immunostaining for inhibin- $\alpha(B)$, calretinin $(C)$, and CD56 (D). In benign sex cord-stromal tumors, only some stromal cells displayed weakly nuclear or cytoplasmic p16 immunoreactivity (E). Low-power magnification of adult granulosa cell tumors showing uniform and strong stromal p16 immunoreactivity. The tumor cells did not exhibit p16 expression $(F)$. At medium-power magnification, p16 expression was observed in both the nucleus and cytoplasm of the spindle-shaped stromal cells $(G)$. In a few cases of adult granulosa cell tumors, p16 protein was localized within the tumor cells, most of which exhibited weak cytoplasmic immunoreactivity (H). Original magnifications: $F, \times 40 ; A, B, D, E$, and $G, \times 100 ; C$ and $H, \times 200$. 
Table II. Stromal p16 expression in primary and metastatic adult granulosa cell tumors of the ovary.

\begin{tabular}{|c|c|c|c|c|c|}
\hline \multirow[t]{2}{*}{ Category } & \multirow[t]{2}{*}{ Total, $\mathrm{n}$} & \multicolumn{4}{|c|}{ Stromal p16 immunoreactivity, n (\%) } \\
\hline & & Negative & Weakly positive & Moderately positive & Strongly positive \\
\hline Nonpathological ovary & 5 & $5(100.0)$ & $0(0.0)$ & $0(0.0)$ & $0(0.0)$ \\
\hline Benign SCST & 13 & $10(76.9)$ & $3(23.1)$ & $0(0.0)$ & $0(0.0)$ \\
\hline Primary AGCT & 13 & $0(0.0)$ & $2(15.4)$ & $7(53.8)$ & $4(30.8)$ \\
\hline Metastatic AGCT & 11 & $0(0.0)$ & $0(0.0)$ & $3(27.3)$ & $8(72.7)$ \\
\hline
\end{tabular}

AGCT: Adult granulosa cell tumor; SCST: sex cord-stromal tumor.

positive for inhibin- $\alpha(24 / 24,100.0 \%$; Figure 1B), calretinin (22/24, 91.7\%; Figure 1C), CD56 (21/24, 87.5\%; Figure 1D), CD99 (membranous staining pattern; 18/24, 75.0\%), and smooth muscle actin $(24 / 24,100.0 \%)$, but were negative for epithelial membrane antigen $(0 / 24,0.0 \%)$.

Stromal p16 expression in primary and recurrent adult granulosa cell tumors. Stromal p16 immunoreactivity in five nonpathological ovaries, 13 benign sex cord-stromal tumors, and 24 adult granulosa cell tumors are presented in Table II. Representative photomicrographs of stromal p16 expression are shown in Figure 1. All cases of nonpathological ovarian stroma and $10(76.9 \%)$ cases of benign sex cord-stromal tumor were negative for p16 immunoreactivity. Normal granulosa and theca cells within ovarian follicles or follicle cysts did not exhibit p16 expression. The remaining three $(23.1 \%)$ benign sex cord-stromal tumors exhibited weakly positive p16 expression (Figure 1E). Some scattered spindleor stellate-shaped stromal cells demonstrated weak cytoplasmic p16 immunoreactivity. There was no significant difference in stromal p16 expression between nonpathological ovaries and benign sex cord-stromal tumors $(p=0.522)$. In contrast, the majority of primary adult granulosa cell tumors showed at least moderately positive p16 expression in the peritumoral stroma. Of the 13 cases of primary adult granulosa cell tumors, four $(30.8 \%)$ and seven $(53.8 \%)$ cases showed strongly (Figure $1 \mathrm{~F}$ ) and moderately positive p16 expression, respectively. Most of the p16-positive stromal cells demonstrated moderate to strong staining intensities (Figure 1G). Stromal p16 expression was significantly increased in primary adult granulosa cell tumors compared with those in nonpathological ovaries $(p<0.001)$ and benign sex cord-stromal tumors $(p<0.001)$. All cases of recurrent adult granulosa cell tumors showed at least moderately positive p16 expression in the peritumoral stroma. Of the 11 cases of recurrent adult granulosa cell tumors, three (27.3\%) and eight $(72.7 \%)$ cases showed strongly and moderately positive p16 expression, respectively. Compared to nonpathological ovaries $(p<0.001)$ and benign sex cord-stromal tumors $(p<0.001$; Figure 2$)$, recurrent adult granulosa cell

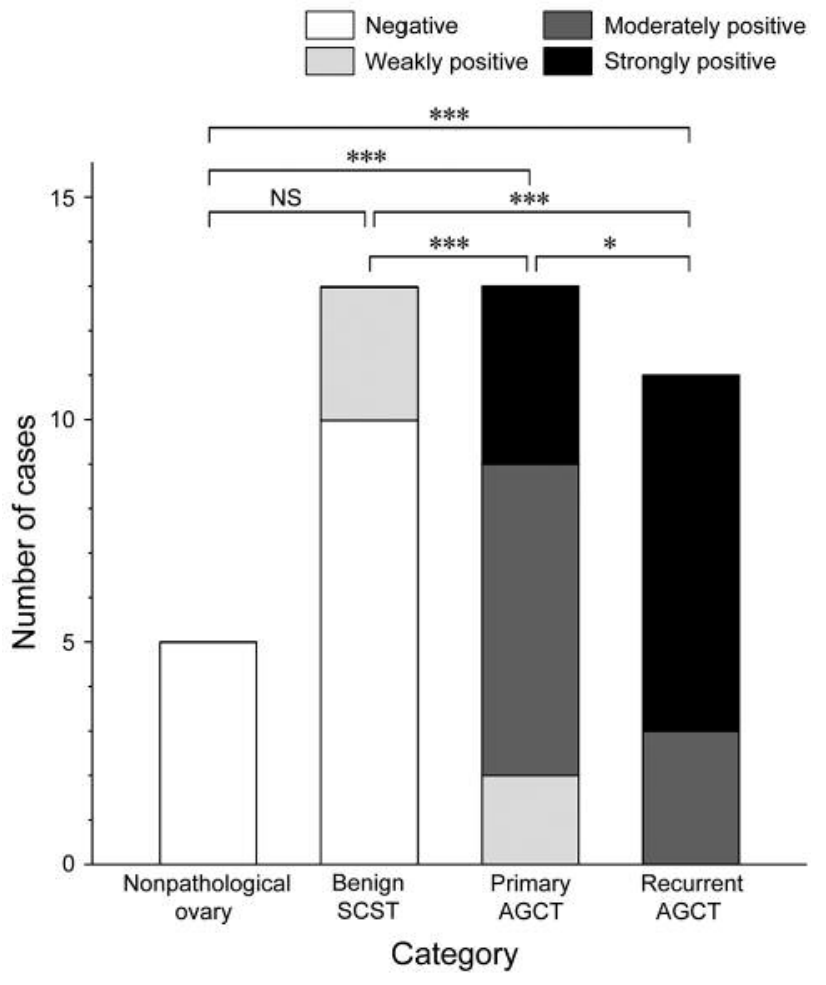

Figure 2. Differences in stromal p16 expression between nonpathological ovaries, benign sex cord-stromal tumors (SCSTs), and primary and recurrent adult granulosa cell tumors (AGCTs). Stromal p16 expression of primary adult granulosa cell tumors was significantly higher than those of nonpathological ovaries and benign sex cordstromal tumors. In addition, recurrent adult granulosa cell tumors had significantly increased stromal p16 immunoreactivity as compared to primary adult granulosa cell tumors. NS: Not statistically significant; *significantly different at $p<0.05$; ***significantly different at $p<0.001$.

tumors displayed significantly increased stromal p16 expression. In addition, the difference in stromal p16 expression between primary and recurrent adult granulosa cell tumors was statistically significant $(p=0.032)$. Stromal p16 expression was uniform throughout the tumors, with only minimal variations in the staining intensities between 
different areas. There was no significant intratumoral heterogeneity associated with p16 immunoreactivity.

Two $(2 / 13,15.4 \%)$ and three $(3 / 11,27.2 \%)$ cases of primary and recurrent adult granulosa cell tumors, respectively, exhibited patchy, weak to moderate cytoplasmic p16 immunoreactivity in the tumor cells (Figure $1 \mathrm{H}$ ). The p16-positive tumor cells did not display significant cytological atypia or architectural abnormalities.

\section{Discussion}

A novel finding reported in this preliminary study is the significant increase in stromal p16 expression in primary and recurrent adult granulosa cell tumors. We observed that all cases of non-pathological ovary and benign sex cord-stromal tumors had p16 immunostaining scores of $\leq 3$ (negative or weakly positive), whereas primary adult granulosa cell tumors had scores of $\geq 4$ (at least moderately positive) in $84.6 \%(11 / 13)$ of the cases examined. Moreover, $30.8 \%$ (4/13) of the cases had scores $\geq 8$ (strong positive). Stromal p16 expression was significantly higher in primary adult granulosa cell tumors than in nonpathological and benign sex cord-stromal tumors. These findings are consistent with those of our previous studies demonstrating stromal p16 overexpression in ovarian and endometrial carcinomas (18, 19). Compared to benign and borderline ovarian tumors, ovarian carcinomas had significantly elevated p16 expression levels in the peritumoral stroma. We also observed significantly higher levels of stromal p16 expression in endometrial carcinomas than in benign and precancerous lesions. Our observation of stromal p16 overexpression in adult granulosa cell tumors suggests that p16 may be involved in the development of adult granulosa cell tumors in the tumor microenvironment through its overexpression in stromal cells. In addition, we noted that stromal p16 expression in recurrent adult granulosa cell tumors was significantly higher than that in primary adult granulosa cell tumors. All cases of recurrent adult granulosa cell tumors exhibited moderately $(3 / 11,27.3 \%)$ or strongly positive $(8 / 11,72.7 \%)$ p16 expression. This finding raises the possibility that p16 may play a role in the progression and recurrence of adult granulosa cell tumors. Some previous studies have reported an increased p16 expression at the invasive tumor front of basal cell carcinomas, colorectal carcinomas, and endometrial carcinomas (23-25). These results suggest that p16 may be involved in tumor invasion and progression and support the hypothesis that p16 protein promotes invasiveness through interactions with other molecules related to tumor cell migration and invasion (6, $23,24,26,27)$. Another study on p16 expression in the stroma of ductal breast carcinoma in situ (28) provided evidence that ductal carcinoma in situ with high stromal p16 expression tended to show estrogen receptor negativity and high Ki-67 labeling indices. In addition, it was reported that high stromal p16 expression was a strong independent predictor of ductal carcinoma in situ recurrence with a higher hazard ratio than other established prognostic markers. These findings are in agreement with our data. The p16 protein is an inhibitor of cell growth in response to various stress stimuli, such as DNA damage, oxidative stress, or hyperproliferative signals. Therefore, p16 induces cellular senescence, such that stromal p16 overexpression is indicative of stromal cell senescence. On the basis of the results of previous studies (29-31), we postulated that senescent stroma can contribute to disease progression by secreting inflammatory mediators, cytokines, and enzymes such as proteases, providing a mechanism through which p16-positive stroma contributes to tumor progression. To confirm our preliminary results, it will be necessary to analyze stromal p16 expression using a larger number of adult granulosa cell tumor samples.

We observed p16 expression in the cytoplasm of tumor cells in five cases, including two primary and three recurrent adult granulosa cell tumors. In contrast, there was no p16 immunoreactivity in normal granulosa cells within the follicles, follicle cysts, or corpus luteum cysts. Recent studies have suggested that tumor cell p16 may play a role in both cellular proliferation and tumor progression. In the colon, p16 immunoreactivity was very low in the normal mucosa, with a progressively higher expression in aberrant crypt foci, non-serrated adenomas, primary colonic carcinomas, and metastatic tumors $(15,32)$. A similar staining pattern was observed in skin, where p16 expression increased from relatively low levels in premalignant lesions to high levels in in situ and infiltrating carcinomas (33), and in the breast, where negative or low expression is seen in normal ductal epithelium, together with a progressive increase in benign lesions and carcinomas (17, 34). Furthermore, it has been suggested that p16 can be used in the differential diagnosis of uterine leiomyosarcoma from leiomyoma and smooth muscle tumors of uncertain malignant potential based on p16 overexpression in leiomyosarcoma (35). Atkins et al. observed that most uterine leiomyosarcomas strongly and diffusely expressed p16, whereas leiomyoma had focal p16 staining, and none of the normal myometrium samples expressed p16 (35). In this study, statistical analyses could not be performed due to the limited numbers of cases with tumor cell p16 expression. Further studies on the clinicopathological significance of p16 expression within the tumor cells of adult granulosa cell tumors with a larger patient cohort are necessary.

In conclusion, we investigated the stromal p16 expression in ovarian adult granulosa cell tumors by immunohistochemical staining. We found that stromal p16 expression levels of recurrent adult granulosa cell tumors were significantly higher than those of primary adult granulosa cell tumors, which in 
turn were significantly higher than those of non-pathological ovaries and benign sex cord-stromal tumors. Stromal p16 expression was absent or weak in nonpathological ovaries and benign sex cord-stromal tumors, whereas the majority of adult granulosa cell tumors exhibited diffuse and moderate-to-strong p16 immunoreactivity, suggesting that stromal p16 expression may be involved in the development and progression of adult granulosa cell tumors. Significantly higher stromal p16 expression levels in recurrent adult granulosa cell tumors as compared to those in primary adult granulosa cell tumors raise the possibility that p16 overexpression in the peritumoral stroma is associated with aggressive oncogenic behavior of adult granulosa cell tumors. Further studies are necessary to confirm our preliminary results.

\section{Acknowledgements}

This research was supported by the Basic Science Research Program through the National Research Foundation of Korea and funded by the Ministry of Education (2016R1D1A1B03935584).

\section{References}

1 Ugianskiene A, Grove A and Soegaard-Andersen E: Adult granulosa cell tumor of the ovary: a retrospective study of 37 cases. Eur J Gynaecol Oncol 35: 621-624, 2015.

2 Huang BS, Sun HD, Hsu YM, Chang WH, Horng HC, Yen MS, Chao KC, Edmond Hsieh SL and Wang PH: Clinical presentation and outcome of adult-type granulosa cell tumors: a retrospective study of 30 patients in a single institute. J Chin Med Assoc 77: 21-25, 2014

3 Mancari R, Portuesi R and Colombo N: Adult granulosa cell tumours of the ovary. Curr Opin Oncol 26: 536-541, 2014.

4 Shim SH, Kim DY, Lee SW, Park JY, Kim JH, Kim YM, Kim YT and Nam JH: Laparoscopic management of early-stage malignant nonepithelial ovarian tumors: surgical and survival outcomes. Int J Gynecol Cancer 23: 249-255, 2013.

5 Schumer ST and Cannistra SA: Granulosa cell tumor of the ovary. J Clin Oncol 21: 1180-1189, 2003.

6 Romagosa C, Simonetti S, Lopez-Vicente L, Mazo A, Lleonart ME, Castellvi $\mathrm{J}$ and Ramon y Cajal S: p16(INK4A) overexpression in cancer: a tumor-suppressor gene associated with senescence and high-grade tumors. Oncogene 30: 20872097, 2011.

7 Serrano M: The tumor-suppressor protein p16 ${ }^{\mathrm{INK} 4 \mathrm{~A}}$. Exp Cell Res 237: 7-13, 1997.

8 Pei XH and Xiong Y: Biochemical and cellular mechanisms of mammalian CDK inhibitors: a few unresolved issues. Oncogene 24: 2787-2795, 2005.

9 Serrano M: Cancer regression by senescence. N Engl J Med 356: 1996-1997, 2007.

10 Weber JD, Jeffers JR, Rehg JE, Randle DH, Lozano G, Roussel MF, Sherr CJ and Zambetti GP: p53-Independent functions of the p19(ARF) tumor suppressor. Genes Dev 14: 2358-2365, 2000.

11 Kurman RJ, Carcangiu ML, Herrington CS and Young RH: WHO Classification of Tumours of Female Reproductive Organs. Lyon, France: IARC, 2014.
12 Mulvany NJ, Allen DG and Wilson SM: Diagnostic utility of p16INK4A: a reappraisal of its use in cervical biopsies. Pathology 40: 335-344, 2008.

13 Waxman AG, Chelmow D, Darragh TM, Lawson $\mathrm{H}$ and Moscicki AB: Revised terminology for cervical histopathology and its implications for management of high-grade squamous intraepithelial lesions of the cervix. Obstet Gynecol 120: 14651471, 2012.

14 Darragh TM, Colgan TJ, Cox JT, Heller DS, Henry MR, Luff RD, McCalmont T, Nayar R, Palefsky JM, Stoler MH, Wilkinson EJ, Zaino RJ, Wilbur DC and Members of LPWG: The Lower Anogenital Squamous Terminology Standardization Project for HPV-Associated Lesions: background and consensus recommendations from the College of American Pathologists and the American Society for Colposcopy and Cervical Pathology. J Low Genit Tract Dis 16: 205-242, 2012.

15 Zhao P, Mao X and Talbot IC: Aberrant cytological localization of p16 and CDK4 in colorectal epithelia in the normal adenoma carcinoma sequence. World J Gastroenterol 12: 6391-6396, 2006.

16 Armes JE, Lourie R, de Silva M, Stamaratis G, Boyd A, Kumar B, Price G, Hyde S, Allen D, Grant P and Venter DJ: Abnormalities of the RB1 pathway in ovarian serous papillary carcinoma as determined by overexpression of the p16(INK4A) protein. Int J Gynecol Pathol 24: 363-368, 2005.

17 Milde-Langosch K, Bamberger AM, Rieck G, Kelp B and Loning T: Overexpression of the p16 cell-cycle inhibitor in breast cancer is associated with a more malignant phenotype. Breast Cancer Res Treat 67: 61-70, 2001.

18 Yoon N, Yoon G, Park CK and Kim HS: Stromal p16 expression is significantly increased in malignant ovarian neoplasms. Oncotarget 7: 64665-64673, 2016.

19 Yoon G, Koh CW, Yoon N, Kim JY and Kim HS: Stromal p16 expression is significantly increased in endometrial carcinoma. Oncotarget 8: 4826-4836, 2017.

20 Schneider-Stock R, Boltze C, Lasota J, Peters B, Corless CL, Ruemmele P, Terracciano L, Pross M, Insabato L, Di Vizio D, Iesalnieks I, Dirnhofer S, Hartmann A, Heinrich M, Miettinen M, Roessner A and Tornillo L: Loss of p16 protein defines highrisk patients with gastrointestinal stromal tumors: a tissue microarray study. Clin Cancer Res 11: 638-645, 2005.

21 Brambilla E, Gazzeri S, Moro D, Lantuejoul S, Veyrenc S and Brambilla C: Alterations of Rb pathway (Rb-p16 INK4-cyclin D1) in preinvasive bronchial lesions. Clin Cancer Res 5: 243-250, 1999.

22 Ayhan S, Isisag A, Saruc M, Nese N, Demir MA and Kucukmetin NT: The role of pRB, p16 and cyclin D1 in colonic carcinogenesis. Hepatogastroenterology 57: 251-256, 2010.

23 Jung A, Schrauder M, Oswald U, Knoll C, Sellberg P, Palmqvist R, Niedobitek G, Brabletz T and Kirchner T: The invasion front of human colorectal adenocarcinomas shows co-localization of nuclear beta-catenin, cyclin D1 and p16 INK4A and is a region of low proliferation. Am J Pathol 159: 1613-1617, 2001.

24 Svensson S, Nilsson K, Ringberg A and Landberg G: Invade or proliferate? Two contrasting events in malignant behavior governed by $\mathrm{p} 16(\mathrm{INK} 4 \mathrm{a})$ and an intact $\mathrm{Rb}$ pathway illustrated by a model system of basal cell carcinoma. Cancer Res 63: 1737-1742, 2003.

25 Horree N, van Diest PJ, Sie-Go DM and Heintz AP: The invasive front in endometrial carcinoma: higher proliferation and associated derailment of cell cycle regulators. Hum Pathol 38: 1232-1238, 2007. 
26 Palmqvist R, Rutegard JN, Bozoky B, Landberg G and Stenling $\mathrm{R}$ : Human colorectal cancers with an intact p16/cyclin D1/pRb pathway have up-regulated p16 expression and decreased proliferation in small invasive tumor clusters. Am J Pathol 157: 1947-1953, 2000.

27 Natarajan E, Saeb M, Crum CP, Woo SB, McKee PH and Rheinwald JG: Co-expression of p16(INK4A) and laminin 5 gamma2 by microinvasive and superficial squamous cell carcinomas in vivo and by migrating wound and senescent keratinocytes in culture. Am J Pathol 163: 477-491, 2003.

28 Witkiewicz AK, Rivadeneira DB, Ertel A, Kline J, Hyslop T, Schwartz GF, Fortina $\mathrm{P}$ and Knudsen ES: Association of $\mathrm{RB} / \mathrm{p} 16$-pathway perturbations with DCIS recurrence: dependence on tumor versus tissue microenvironment. Am J Pathol 179: 1171-1178, 2011.

29 Davalos AR, Coppe JP, Campisi J and Desprez PY: Senescent cells as a source of inflammatory factors for tumor progression. Cancer Metastasis Rev 29: 273-283, 2010.

30 Coppe JP, Desprez PY, Krtolica A and Campisi J: The senescence-associated secretory phenotype: the dark side of tumor suppression. Annu Rev Pathol 5: 99-118, 2010.

31 Moritani S, Ichihara S, Hasegawa M, Iwakoshi A, Murakami S, Sato T, Okamoto T, Mori Y, Kuhara H and Silverberg SG: Stromal p16 expression differentiates endometrial polyp from endometrial hyperplasia. Virchows Arch 461: 141-148, 2012.
32 Dai CY, Furth EE, Mick R, Koh J, Takayama T, Niitsu Y and Enders GH: p16(INK4a) expression begins early in human colon neoplasia and correlates inversely with markers of cell proliferation. Gastroenterology 119: 929-942, 2000.

33 Nilsson $K$ and Landberg G: Subcellular localization, modification and protein complex formation of the CDKinhibitor p16 in $\mathrm{Rb}$-functional and $\mathrm{Rb}$-inactivated tumor cells. Int J Cancer 118: 1120-1125, 2006.

34 Di Vinci A, Perdelli L, Banelli B, Salvi S, Casciano I, Gelvi I, Allemanni G, Margallo E, Gatteschi B and Romani M: p16(INK4a) promoter methylation and protein expression in breast fibroadenoma and carcinoma. Int J Cancer 114: 414-421, 2005.

35 Atkins KA, Arronte N, Darus CJ and Rice LW: The use of p16 in enhancing the histologic classification of uterine smooth muscle tumors. Am J Surg Pathol 32: 98-102, 2008.

Received March 30, 2017

Revised April 11, 2017

Accepted April 19, 2017 